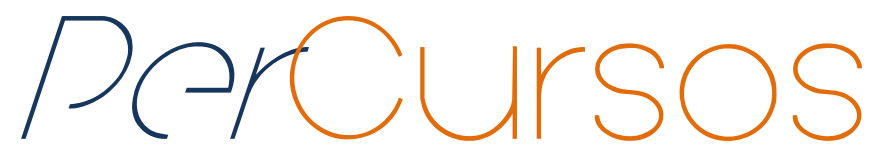

\title{
Percursos da formação inicial em portfólio e blog ${ }^{1}$
}

\begin{abstract}
Resumo
A pesquisa analisa as intersecções entre formação inicial e as reflexões sobre as práticas docentes registradas em blog e portfólio por bolsistas PIBID Subprojeto - Pedagogia/FACOS, realizada em escolas da rede pública do Litoral Norte do Rio Grande do Sul. Fundamentada nas ideias de Lévy (1996), que situa e compreende a rede como tempo/lugar de conexão entre pessoas com interesses comuns, e Goulart (2011), que considera o portfólio um instrumento que entrelaça a ação de escrever e as experiências dos sujeitos para produzir novos conhecimentos, busca-se analisar o aprendizado das bolsistas a partir da reflexão que fazem do processo vivido na prática docente. Os escritos produzidos pelas bolsistas contemplam reflexão, tanto do planejamento quanto das práticas registrados em blogs e portfólios, os quais constituem rede física e virtual que valoriza e amplia constatações e análises da caminhada que envolve a formação profissional das bolsistas. As práticas pedagógicas produzidas na escola abrangem atividades propostas em oficinas de aprendizagem, com turmas de primeiro e segundo ano do Ensino Fundamental, tendo como foco a alfabetização e o letramento, articulados ao uso de recursos tecnológicos contemporâneos. Os resultados indicam transformações no percurso das bolsistas em relação à escrita acadêmica, à articulação dos conhecimentos da formação teórica às práticas pedagógicas. Atitudes que valorizam as leituras acadêmicas, a elaboração de projetos de investigação próprios ressignifica aprendizagens e experiências vivenciadas no contexto escolar. Essas construções reverberam no desenvolvimento de novas ações e posicionamentos mais contundentes no sentido do reconhecimento do processo de alfabetização nas leituras de mundo.
\end{abstract}

Palavras-chave: Portfólio; Blog; Formação Docente; Oficinas de Aprendizagem.

\section{Para citar este artigo:}

SOUZA, Anilda Machado de; GOULART, Ligia Beatriz. Percursos da formação inicial em portfólio e blog. Revista PerCursos, Florianópolis, v. 17, n.35, p. 160 - 174, set./dez. 2016.

\section{DOI: 10.5965/1984724617352016160}

http://dx.doi.org/10.5965/1984724617352016160

\footnotetext{
${ }^{1}$ Projeto de pesquisa "PIBID - Pedagogia da Faculdade Cenecista de Osório.", com apoio da Coordenação de Aperfeiçoamento de Pessoal de Nível Superior - CAPES/MEC.
}

Anilda Machado de Souza

Mestre em Educação pela

Pontifícia Universidade Católica

do Rio Grande do Sul - PUCRS.

Professora da Faculdade

Cenecista de Osório - FACOS.

Brasil

souzah@hotmail.com

\section{Ligia Beatriz Goulart}

Doutora em Geografia

Universidade Federal do Rio

Grande do Sul - UFRGS.

Professora da Faculdade

Cenecista de Osório - FACOS.

Brasil

goulartlb@hotmail.com 


\title{
Initial training trajectories in portfolio blog
}

\begin{abstract}
The research examines the intersections between initial training and reflections on the teaching practices recorded in blog and portfolio by scholars PIBID Subproject - Pedagogy / FACOS held in public schools of the North Coast of Rio Grande do Sul. Based on Lévy (1996), which makes a comprehension about net as a connection time/place with interests in common, and Goulart (2011), who considers portfolio a instrument that interweaves writing action and experiences to produce knowledge, analyzing the scholarship students learning from the reflection they do about the lived process in teaching practice. The texts produced by the scholarship students talk about their own reflections, planning and teaching practices, posted in blogs and portfolios, composing physical and virtual net which improves the results researched by the students and their professional training. The pedagogical practices developed in school embrace activities proposed in learning workshops, with first and second grades in elementary school focused in literacy using technological resources. The results indicate transformations in the scholarship students trajectory articulating knowledge from theory and pedagogical practices. Attitudes that improve academic reading, projects elaboration reframe learning and experiences lived at school. These results clarify developing new actions and scathing behaviors recognizing literacy in the world readings.
\end{abstract}

Keywords: Portfolio; Blog; Teacher Training; Learning Workshops. 


\section{Palavras iniciais}

O Programa Institucional de Iniciação à Docência tem a finalidade de incentivar a formação docente inserindo os licenciandos no universo das escolas da rede pública de educação. Também, oportuniza a vivência de práticas docentes de caráter inovador e integrado, com ênfase em experiências que transitem entre a superação dos problemas relacionados ao processo de ensinar e aprender e a inovação de práticas pedagógicas que incluam a tecnologia em favor da aprendizagem. Ainda visa aproximar a escola, a comunidade e a IES, buscando criar propostas que qualifiquem a educação e promovam a formação cidadã, bem como que haja o desenvolvimento de ações que evidenciem o respeito às diversidades individuais e coletivas, a valorização da experimentação e das curiosidades, contribuindo para redefinir as trajetórias da educação básica.

$\mathrm{Na}$ intenção de compreender as intersecções entre formação inicial e o exercício reflexivo sobre a prática docente de bolsistas que atuam no Programa Institucional de Bolsa de Iniciação à Docência, no subprojeto de Pedagogia da Faculdade Cenecista de Osório, realizada em escolas da rede pública do Litoral Norte do Rio Grande do Sul, foram analisados os escritos reflexivos de blog e portfólio, elaborados por cinco bolsistas.

O blog é uma página da Internet usada para registro de atividades sistemáticas ou eventuais. Cada registro constitui uma postagem, por isso é conhecido como diário online ou virtual. Já o portfólio, neste contexto, consiste em escritos físicos construídos a partir das práticas docentes. Tanto o blog como o portfólio tem a finalidade de registrar o percurso das aprendizagens, construídas a partir de oficinas realizadas pelas bolsistas, com turmas de primeiro e segundo ano do Ensino Fundamental e dos encontros de orientação com a coordenação e as colegas.

O processo de escrita em blogs e portfólios contribui para reflexão sobre a formação docente das bolsistas do PIBID - Pedagogia e constitui-se como o norte da investigação. A partir desta questão, os escritos das bolsistas são examinados, com a finalidade de produzir os resultados destacados neste artigo.

As observações, constatações e apreciações, tanto do planejamento quanto da prática pedagógica das bolsistas envolvidas neste processo, têm valorizado e ampliado 
percepções sobre o exercício docente no contexto do processo de alfabetização, um olhar que inclui preocupação com a leitura e a escrita. Para além dessa questão, significa também, pensar a alfabetização na perspectiva das diferentes áreas do conhecimento, reconhecendo seu potencial para ampliar e aprofundar os entendimentos sobre o mundo, tanto das bolsistas quanto dos alunos com os quais atuam. Nesse contexto, cabe destacar os atravessamentos que se impõem no ato de ensinar e de aprender a ler e a escrever no cotidiano das crianças da periferia e as implicações na construção das trajetórias das bolsistas.

Fundamentada nas ideias de Lévy (1996), que situa e compreende a rede como tempo/lugar de conexão entre pessoas com interesses comuns, e Goulart (2011), que considera o portfólio um instrumento que entrelaça a ação de escrever e as experiências dos sujeitos para produzir novos conhecimentos, busca-se analisar o aprendizado das bolsistas a partir daquilo que escrevem sobre o processo vivido na prática docente.

\section{Intersecções/percursos}

Além de situar a escola como espaço articulador de práticas pedagógicas, o subprojeto de Pedagogia - Faculdade Cenecista de Osório - coloca as bolsistas em permanente movimento, incitando descobertas e novos empreendimentos. No contexto de quatro escolas municipais do Litoral Norte do Rio Grande do Sul, as bolsistas efetivam a proposta do PIBID/Pedagogia por meio da problematização, experimentação e reflexão sobre o cotidiano escolar e, especialmente, quando produzem tramas na rede que contêm aprendizagens do "viver professora" e do "ser aluna" do curso de Pedagogia. Também planejam, executam, tomam decisões sobre suas práticas, bem como avaliam os resultados produzindo análises que encaminham novas iniciativas. No movimento do “viver o espaço escolar" experimentam o "ser professora” em todas as suas facetas. Destacam-se as ações que contemplam o planejamento de atividades pedagógicas articuladas a questões específicas emanadas de observações sistemáticas do cotidiano das turmas de primeiro ou segundo ano, eleitas como lugar de atuação. 
Neste processo de implementação da prática pedagógica, que considera o cotidiano como referência para articular saberes empíricos e saberes científicos, as bolsistas revisitam temas como a leitura e a escrita, em suas diferentes linguagens, guiadas pela concepção de professor alfabetizador.

Sobre o professor alfabetizador, Soares (2011) afirma que

[...] tem uma grande especificidade, e exige uma preparação do professor que o leve a compreender todas as facetas (psicológica, psicolinguística, sociolinguística e linguística) e todos os condicionantes (sociais, culturais, políticos) do processo de alfabetização, que o leve a saber operacionalizar essas diversas facetas (sem desprezar seus condicionantes) em métodos e procedimentos de preparação para a alfabetização, em elaboração e uso adequados de materiais didáticos, e, sobretudo, que o leve a assumir uma postura política diante das implicações ideológicas do significado e do papel atribuído à alfabetização. (SOARES, 2011, p. 24)

A condição de professora alfabetizadora, como analisa Soares, envolve a apropriação dos conhecimentos científicos ligados à alfabetização, mas também as condições que se constroem na vivência do processo e na interação escola-aluno-sujeito. Essa trama alimenta e produz a professora alfabetizadora. Nesse sentido, uma das bolsistas comenta como entende esse desafio.

Percebi o quanto é difícil ser um professor alfabetizador, com alunos em níveis diferentes em uma mesma sala de aula. A dificuldade está em acompanhar cada um, pensar em atividades que façam com que esses alunos evoluam em suas aprendizagens, pensando na turma e na sua individualidade. (PORTFÓLIO 1)

As palavras da bolsista ilustram algumas demandas que se estabelecem no processo. Neste sentido, foi instituído, com periodicidade semanal, o Seminário de Formação Permanente, espaço/tempo dos contatos, das trocas, das reflexões, da sistematização do conhecimento teórico, das articulações e das retomadas. Trata-se, assim, de contexto formador que contempla atividades de leitura e aprofundamento 
teórico focados na alfabetização, nas diferentes linguagens, com ênfase nas tecnologias da informação. Para tanto, são propostas análises de documentos como as Diretrizes Curriculares Nacionais (DCN), Avaliação Nacional de Alfabetização (ANA), Projeto Pedagógico, Regimento Escolar, Planos de Estudos, bem como atividades relacionadas à observação, monitoria, planejamento e execução de oficina pedagógica, tendo em vista as propostas efetuadas por cada uma das bolsistas.

Nesses seminários, orientadora e bolsistas desenvolvem ações relacionadas à inserção na escola, discutindo as singularidades dos contextos em que cada uma experimenta o ser professora. Expressam opiniões e vivências no intuito de contribuir para o enfrentamento dos desafios presentes nas diferentes realidades, tanto em relação às práticas pedagógicas quanto às relações interpessoais, vínculos com os sujeitos professores e os alunos. A rede captura fios que criam caminhos, alternativas, olhares e soluções complexificando o emaranhado da trama.

Destacam-se necessidades oriundas do movimento da escola e das práticas das bolsistas, tais como estudos sobre a violência, a indisciplina, os fundamentos da alfabetização, o uso das tecnologias na sala de aula, etc. Essas ações contribuem para alimentar as análises do viver a escola para além da sala de aula, para examinar alternativas aos enfrentamentos cotidianos na condição de alfabetizadoras, como explicita a bolsista neste fragmento.

Nesse período, percebi como é importante a formação continuada de um professor. O quanto é preciso buscar o conhecimento de diversas formas, seja em livros, internet, cursos e principalmente manter uma boa relação com os colegas de trabalho, conversando com o professor anterior da turma para obter informações sobre as suas aprendizagens. $\mathrm{E}$ também o quanto a prática, o dia a dia de sala de aula ensina, servindo de norte para os trabalhos que vão ser desenvolvidos. (PORTFÓLIO 1)

O processo de reflexão sobre a prática e a busca constante aos documentos revisitando os materiais produzidos, os objetivos propostos e os resultados alcançados remetem ao processo de formação inicial e permanente dos sujeitos. As aprendizagens 
construídas nesse processo precisam traduzir preocupação com a formação do sujeito professor. Espera-se um professor criativo, alguém especialmente aberto ao novo, colaborativo e solidário com os empreendimentos coletivos, alguém que enfrente os desafios do cotidiano buscando soluções autônomas e que coloque a educação e os educandos como protagonistas do processo.

A expressão das necessidades, pensamentos, ponderações, conversas consigo e os relatos daquilo que acontece nas salas de aulas constituem os registros das bolsistas. Eles corporificam os blogs, esse diário virtual da Web 2.0, que carrega, ao mesmo tempo, o individual e o coletivo, assim definido por Gomes (2005):

É uma página na Web que se pressupõe ser actualizada com grande frequência através da colocação de mensagens - que se designam "posts" - constituídas por imagens e/ou textos normalmente de pequenas dimensões (muitas vezes incluindo links para sites de interesse e/ou comentários e pensamentos pessoais do autor) e apresentadas de forma cronológica, sendo as mensagens mais recentes normalmente apresentadas em primeiro lugar. (GOMES, 2005, p.311)

A caminhada que empreendem é registrada nos blogs individuais e que constituem as tramas da rede virtual, pois ampliam as conexões na web e rompem as fronteiras das salas de aula promovendo outras aprendizagens. Alimentados sistematicamente a partir da necessidade e interesse de seus autores, os blogs vão compondo um significativo conjunto de informações sobre as trajetórias individuais. Ainda que a escrita não seja totalmente autoral, as rotas que produzem caracterizam diferentes níveis de participação e apreensão do processo.

Os portfólios também têm papel relevante na formação docente, pois ao conectar saberes empíricos, vivências acadêmicas e práticas pedagógicas para expressar entendimentos, qualificam a escrita e favorecem o processo de metacognição, tão importante às professoras em formação. Nesse sentido, o portfólio se mostra um instrumento importante, porque é o lugar em que, segundo Goulart (2011): 
[...] os alunos relatam suas aprendizagens, compilam materias produzidos e elaboram uma espécie de pasta informativa sobre os acontecimentos de sua vida escolar. O portfólio é um instrumento de avaliação diferenciado e consistente porque permite um olhar mais abrangente sobre o processo de cada aluno, vislumbrando o aluno em sua totalidade, seus saberes empíricos e teóricos, as soluções que produz para os problemas, as relações que estabelece com as diferentes informações, as contextualizações que faz e como integra as diferentes áreas do conhecimento. É, pois, um espaço que permite perceber o aluno em sua complexidade. (GOULART, 2011,p. 17)

As bolsistas registram num portfólio, percepções deste percurso, o que significa escrever sobre a vivência docente e as aprendizagens construídas enquanto acadêmicas do curso de Pedagogia. "Contemplar as crianças lendo e escrevendo de forma autônoma, desperta o prazer de ensinar" (PORTFÓLIO 3). "A leitura é muito cobrada dos alunos, mas não é ensinada com prazer, ou até mesmo apresentada aos alunos como um meio de aprender, se divertir, imaginar..." (PORFÓLIO 1). Também expressam necessidades, sentimentos, percepções sobre suas atuações, expectativas e tudo aquilo que consideram relevante para a compreensão do processo em que estão imersas, especialmente aspectos relevantes do ensinar e aprender num contexto alfabetizador. Estes registros constituem tentativas de mapear os movimentos das aprendizagens das bolsistas por meio de dados reflexivos sobre a sua perspectiva de professor alfabetizador em formação.

É importante referir que os escritos do portfólio são lidos sistematicamente pela orientadora e pela bolsista buscando ampliar as reflexões, corrigir rotas e redefinir caminhos, tanto pedagógicos quanto da escrita autoral, como comenta uma das bolsistas em relação a sua experiência: “[...] me senti bem amparada e instruída pela professora, que além de dar referências teóricas fundamentais para a elaboração do projeto, não cansa de ler, reler e qualificar meu trabalho [...]" (PORTTFÓLIO 1). 


\section{Entrelaços teóricos}

O processo de formação de professores não é algo que se faz apenas na universidade, por isso as experiências que reportam à sala de aula e ao universo prático da escola ganham importância para as bolsistas e constituem um espaço de transformação daquilo que aprendem no ambiente acadêmico. $O$ entrelaçamento das vivências do estar na escola, associadas aos conhecimentos produzidos no curso, ganha significado e contribui para a formação da futura professora num nível diferenciado. As palavras da bolsista ilustram essa ideia:

Uma das questões, para mim, de extrema relevância é a oportunidade proporcionada pelo PIBID, onde posso relacionar teorias vistas na universidade e a prática vivenciada na sala de aula, convivendo com a realidade escolar e aprendendo formas de superar os obstáculos que surgem durante o processo de aprendizagem. (PORTÓLIO 2)

Viver a escola em toda a sua complexidade permite entender o significado do ser professor no contexto atual. Entende-se que formar docentes para atender à diversidade da sala de aula, permeada por um universo de transformações sociais, culturais, tecnológicas, econômicas e políticas é um dos desafios do curso de Pedagogia. Daí a importância de aproximar os futuros professores daquilo que será seu desafio como profissionais da educação e, assim, prepará-los para nunca estarem preparados: seu lugar será o de permanente aprendiz, o que implica em leituras contextualizadas ao espaço vivido e reflexões sobre as ações, inspiradas nas leituras pedagógicas. Esse novo paradigma, como diz Behrens (2006), pressupõe que o sujeito em formação

[...] na ação docente, necessita reconhecer que a complexidade não é apenas um ato intelectual, mas também o desenvolvimento de novas ações individuais e coletivas que permitam desafiar os preconceitos, que lacem novas atitudes para encarar a vida, que gerem situações de enfrentamento dos medos e das conquistas. (BEHRENS, 2006, p. 21) 
Assim, a complexidade escolar só pode ser alcançada na medida em que seja possível pensar o educar numa visão holística em que esteja contemplada a perspectiva em rede. A rede configura-se com um elemento importante porque captura, conecta e acolhe. No pulsar da rede são produzidos conhecimentos, os quais encaminham deslocamentos e constroem ações. Dessa tessitura emanam saberes, amizades, incentivos, ajudas, contatos, descobertas e reflexões que ressignificam o ser professor.

A rede, como compreende Lévy (1996), é o tempo/lugar de conexão entre as pessoas com interesses comuns porque nela os contatos aprendentes se ampliam. A virtualização das informações desterritorializa os sujeitos e os coloca em diferentes lugares ainda que as referências sejam físicas.

Quando uma pessoa, uma coletividade, um ato, uma informação se virtualizam, eles se tornam "não-presentes", se desterritorializam. Uma espécie de desengate os separa do espaço físico ou geográficos ordinários e da temporalidade do relógio e do calendário. É verdade que não são totalmente independentes do espaço-tempo de referência, uma vez que devem sempre se inserir em suportes físicos e se atualizar aqui ou alhures, agora ou mais tarde. No entanto, a virtualização lhes fez tomar a tangente. (LÉVY, 1996, p. 21)

Nessa perspectiva, foram propostos os blogs como possibilidade de construir conhecimentos articulando saberes, individuais e coletivos. As postagens favorecem a interação entre os leitores por meio de comentários constituindo a rede.

No processo de formação inicial articulada à sala de aula, os blogs se configuram como espaço/tempo do compartilhamento e da socialização das informações e das representações relacionadas ao desafio de ser professora em condições tão particulares, como o são aquelas que ainda estão aprendendo a ensinar. Uma rede que possibilita a interatividade entre as bolsistas por meio do registro de situações de aprendizagens ricas e diversificadas torna-se espaço de reflexão, de crítica, de contraposição, mas também de valorização da trajetória dos sujeitos conectados à rede. As palavras de Santaella (2010) refletem a importância de estar na rede no contexto da contemporaneidade. 
Além de evoluírem internamente, nos territórios da virtualidade, as redes estão hoje também evoluindo nos hibridismos que estabelecem entre os espaços virtuais e os espaços físicos, indiciando que a comunicação humana caminha cada vez mais para a abertura de caminhos plurais que dão a cada indivíduo a possibilidade de trocar, nos seus grupos de eleição, opiniões, questionamentos, pontos de vista, visões de mundo. (SANTAELLA, 2010, p. 268)

O PIBID Pedagogia propõe a perspectiva do trabalho em rede, porque favorece os processos de aprendizagem e a compreensão das subjetividades produzidas neste movimento de estar na escola vivendo o ensinar e aprender, participando do ambiente acadêmico, também aprendendo e ensinando. As trocas produzidas nesse entrelaçamento de discussões teóricas, vivências, experimentos e sentimentos refletem outra condição de formação do professor, especialmente nos anos iniciais.

A imersão na rede favorece a produção de tramas oriundas das observações, leituras, estudos e conversas com as colegas. Por isso a bolsista escreve no blog: “Durante as observações percebo quais os alunos que tem dificuldade em aprender e me pego refletindo sobre a melhor maneira, ou outras maneiras de tentar o que quero deles. Nesse sentido a teoria de Freire (1996, p.118) me norteia" (BLOG 1).

Esse movimento também é evidenciado no registro do percurso vivido por outra bolsista:

[...] as vivências semanais com a turma do $2^{\circ}$ ano do Ensino fundamental da Escola Madre Teresa foram de grandes trocas e aprendizagens, a cada semana fortalecíamos nossa relação, construindo uma nova forma de aprender e reaprender. (BLOG 2)

Assim, as bolsistas esboçam suas reflexões sobre o viver a sala de aula e o contexto da escola associando aquilo que aprendem.

A escolha do blog como instrumento de coleta de informações relaciona-se ao fato de ser esse um espaço singular porque dá visibilidade às subjetividades. Nele encontramse expressos sentimentos, vivências, reflexões, conhecimentos e aprendizagens, tanto 
em relação às experiências da sala de aula quanto do ambiente acadêmico. Assim, reveste de significado porque permite coletar evidências e examinar os processos: traduz as formas de pensar das bolsistas/pibidianas.

Os registros, nesta pesquisa, se configuram como portadores de duas facetas: uma publicizada na web, blogs e, por isso com certas limitações de expressão, já que de domínio público; a outra, a dos escritos no "caderno", mais individualizada traduzindo de forma mais intensa as subjetividades das bolsistas, evidenciando os vínculos com colegas, professores, alunos, orientador, escola: um lugar da conversa que reelabora e reconstrói aprendizagens e conhecimentos e que nem sempre são veiculadas na rede virtual.

A função do portfólio para as pibidiana/bolsista reveste-se de significado porque é o lugar da reflexão e da escrita fluida, uma espécie de diário, com relatos e reflexões sobre seu processo, carregados de sentimentos, considerações, observações e análises sobre si e sua trajetória. Tais evidências constituem importantes indicações do processo de autoprodução, daí sua relevância na formação de professores. As reflexões da bolsista sobre seu processo de aprendizagem deixam claro como acontece a caminhada individual.

[...] quando iniciei o projeto foi bem difícil, eu precisei sentar e criar o meu projeto, sem cópias, precisava ser original e ter um propósito por trás, afinal, era a partir dele que eu desenvolveria toda a minha prática em sala de aula, tive muita dificuldade para realizar o projeto, parecia que não saia do lugar. (PORTÓLIO 3)

Para o orientador/professor, o portfólio possibilita a análise individual e coletiva das bolsistas, pois favorece as articulações e amplia a compreensão dos sujeitos envolvidos no processo. As constatações emanadas dos escritos aprofundam a avaliação porque valorizam aspectos vinculados aos entendimentos individuais, por meio das percepções e seleções de aspectos publicizados nos blogs, mas também a possibilidade de intervenção/provocação do orientador/professor nos escritos ao longo do processo, já que a percepção sobre a própria ação, como refere Goulart (2011) acontece no processo de formação. 
O portfólio enquanto documento escrito era a expressão dos sentimentos das futuras professoras em relação às suas experiências de estágio e, especialmente como elemento de transformação de suas práticas, uma ação-reflexão-ação, agora compartilhada com os leitores do portfólio. Continuava sendo instrumento de avaliação, mas agora ganhava uma nova nuance, também servia para que a aluna/professora pensasse em si enquanto sujeito que ensinava e aprendia. Isso significou e significa a oportunidade de enquanto ensinam, refletirem sobre o ser professor e dessa forma tornarem-se pesquisadoras de sua própria formação (GOULART, 2011, p. 18).

Assim, blog e portfólio constituem-se, ao longo deste processo, significativos instrumentos de valorização das aprendizagens das bolsistas, pois permitem que experimentem pensar sobre aquilo que produzem porque alguém sempre está lendo e analisando. Nesse movimento, a avaliação passa a ser algo que inclui, porque é parte do movimento de produção dos sujeitos e do grupo.

\section{Para não finalizar}

O Índice de Desenvolvimento da Educação Básica (IDEB) e a Avaliação do Rendimento Escolar do Rio Grande do Sul (SAERS) das escolas envolvidas neste subprojeto apontam para a necessidade de repensar as ações pedagógicas em relação ao grupo discente dos anos iniciais do Ensino Fundamental. Isto requer uma postura pedagógica reflexiva e investigativa sobre o cotidiano de ensinar e aprender, um exercício de práticas que inclui todos os atores escolares e articulação das vivências empíricas aos conhecimentos científicos. A reconstrução de práticas pedagógicas desafia as bolsistas a ensinar criando situações mobilizadoras do aprender, orientando o foco para o aluno e, especialmente estabelecendo procedimentos e estratégias que valorizem o movimento, a reflexão, o questionamento entrelaçando pensamentos, ações e contexto.

A inserção nos espaços/tempos da escola oportuniza aos bolsistas do PIBID Pedagogia conhecer realidades diversas, especialmente aquelas das crianças da periferia, onde as condições materiais, afetivas e pedagógicas conspiram contra. Ensinar é uma 
empreitada difícil, e persistir exige propostas afinadas com as demandas daqueles contextos, as quais nem sempre estão ao alcance das bolsistas, ainda que tenham presente aquilo que aprenderam no curso. Articular as experiências aos conhecimentos teóricos e produzir propostas que atendam as necessidades dos alunos, nem sempre é fácil e quase sempre desacomoda. Construir ações em rede favorece os processos de aprender para ensinar. Eis aí, quem sabe a contribuição.

Considerando que a apropriação do conhecimento impõe a necessidade de desenvolver a escrita e a leitura, destacamos como relevante a inserção da cultura digital, por meio dos blogs e dos portfólios. Essa possibilidade de conhecer, ler, escrever e criar novas condições para os sujeitos exercerem práticas de leitura e escrita, altera a condição das formas de interação no mundo e a efetiva participação social. As bolsistas produzem portfólios e blogs tendo como foco as experiências do ambiente escolar, destacando a relevância da formação inicial, como professor alfabetizador, ao vivenciar atividades docentes com crianças em processo de alfabetização.

Para além das possibilidades de desenvolvimento individuais, os blogs e os portfólios servem, também, para auxiliar os bolsistas a refletirem sobre suas práticas por meio da investigação, da colaboração, da cooperação e do compartilhamento tendo em vista ampliar a leitura de mundo, qualificando o processo de alfabetização nas diferentes perspectivas do aprender.

Os resultados, até o momento, indicam o percurso de crescimento das bolsistas em relação à escrita acadêmica, à articulação dos conhecimentos adquiridos no decorrer da formação teórica e à prática com aprofundamento de leituras, à criação de projetos de investigação próprios, reflexões sobre a própria aprendizagem e capacidades de recriar práticas em favor do ato de ler e escrever e, dessa forma, fazendo da participação neste processo um tempo/lugar para apropriação dos conhecimentos e das habilidades que permitam a autoprodução. 


\section{Referências}

BEHRENS, Marilda Aparecida. Portfolio, avaliação e trabalho pedagógico. Petrópolis: Vozes, 2006.

GOMES, M. J. Blogs: um recurso e uma estratégia educativa. In Actas do VII Simpósio Internacional de Informática Educativa. Leiria, 2005, pp. 305-311.

GOULART, Ligia Beatriz. Alunos e professores fazendo geografia: a rede ressignificando informações. Porto Alegre: UFRGS, 2011. 200p. Tese (Doutorado). Programa de PósGraduação em Geografia, Instituto de Geociências, Universidade Federal Do Rio Grande do Sul, Porto Alegre.

LÉVY, Pierre O Que é virtual?. Rio: Editora 34, 1996.

SANTAELLA, Lucia. A ecologia pluralista da comunicação: conectividade, mobilidade, ubiquidade. São Paulo: Paulus, 2010.

SOARES, Magda. As muitas facetas da alfabetização. In: SOARES, Magda. Alfabetização e letramento. 6. ed. São Paulo: Contexto, 2011. 